\title{
Correction to: Reflections about three influential Ambio articles impacting environmental biogeochemistry research and knowledge
}

John W. Farrington (D)

Published online: 28 October 2021

\section{Correction to: Ambio (2021) 50:539-543}

https://doi.org/10.1007/s13280-020-01416-7

In the original article, on the second page, right hand column I incorrectly noted that the person visiting Max Blumer's laboratory who had spoken to me about PCBs interfering with their polycyclic aromatic hydrocarbon analyses in sediments, was Manfred Ehrhardt. It was Walter Giger who had spoken to me (e.g., see Giger and Blumer 1974). Both Walter and Manfred were visitors in Max Blumer's lab during my first years at WHOI. Both provided helpful guidance and advice at the beginning of my career at Woods Hole Oceanographic Institution. I apologize to both for this error.

\section{REFERENCE}

Giger, W. and M. Blumer. 1974. Polycyclic aromatic hydrocarbons in the environment: isolation and characterization by chromatography, visible, ultraviolet, and mass spectrometry. Analytical Chemistry 46: 1663-1671.

Publisher's Note Springer Nature remains neutral with regard to jurisdictional claims in published maps and institutional affiliations.

John W. Farrington $(\bowtie)$

Address: Marine Chemistry and Geochemistry Department, Woods Hole Oceanographic Institution, Woods Hole, MA 02543, USA. e-mail: jfarrington@whoi.edu

The original article can be found online at https://doi.org/10.1007/ s13280-020-01416-7. 